\title{
Carbon Nanofibers: a Versatile Catalytic Support
}

Nelize Maria de Almeida Coelho ${ }^{\text {a }}$ Jomar Livramento Barros Furtado,

Cuong Pham-Huu ${ }^{\mathrm{b}}$, Ricardo Vieira*

${ }^{a}$ Laboratório de Combustão e Propulsão, Instituto Nacional de Pesquisas Espaciais

Rodovia Presidente Dutra, Km 40, 12630-000 Cachoeira Paulista - SP, Brazil

${ }^{\mathrm{b}}$ Laboratoire des Matériaux, Surfaces et Procédés pour la Catalyse, UMR 7515 du CNRS,

Université Louis Pasteur, 25, rue de Becquerel, 67087 Strasbourg Cedex 2, France

Received: December 17, 2007; Revised: February 26, 2008

The aim of this article is present an overview of the promising results obtained while using carbon nanofibers based composites as catalyst support for different practical applications: hydrazine decomposition, styrene synthesis, direct oxidation of $\mathrm{H}_{2} \mathrm{~S}$ into elementary sulfur and as fuel-cell electrodes. We have also discussed some prospects of the use of these new materials in total combustion of methane and in ammonia decomposition. The macroscopic carbon nanofibers based composites were prepared by the CVD method (Carbon Vapor Deposition) employing a gaseous mixture of hydrogen and ethane. The results showed a high catalytic activity and selectivity in comparison to the traditional catalysts employed in these reactions. The fact was attributed, mainly, to the morphology and the high external surface of the catalyst support.

Keywords: carbon nanofibers, catalyst support, macroscopic shaping

\section{Introduction}

The existence of carbon nanofilaments has been observed during the natural gas reforming several decades ago, when these materials were considered as undesirable by-products which led to the catalyst disintegration and plugging. Later, several research groups have been involved in the identification and characterization of this new form of carbon with the aim to reduce its formation ${ }^{1-3}$. However, the interest for these new materials in the field of catalysis only started after the discovery of the carbon nanotubes by Iijima ${ }^{4}$ in 1991 . Nevertheless, two main drawbacks had limited the application of these materials in catalysis: the low yield of carbon nanotubes and the high amount of impurities co-produced by the synthesis routes (electric arc and laser ablation). These restrictions have been fixed by the catalytic method of synthesis suggested by Ebbesen and Ajayan ${ }^{5}$. The method consists basically of a catalytic decomposition of $\mathrm{CO}$ or certain gaseous hydrocarbons on the surface of some transition metals $(\mathrm{Fe}$, $\mathrm{Ni}$ and $\mathrm{Co}$ ) at temperatures between 400 and $800{ }^{\circ} \mathrm{C}$. This catalytic method can be used in the production of either carbon nanotubes or carbon nanofibers. The carbon nanotubes are constituted by graphite layers rolled on itself and parallel to the axis of the tube, displaying a topmost surface constituted by the less reactive basal planes of graphite. The carbon nanofibers are formed by the piling up of graphite layers along the axis of the fiber as a cone form, displaying prismatic planes with high reactivity for the adsorption of the deposited active phase. De Jong and Geus ${ }^{6}$ published an interesting revision about the different methods of synthesis of carbon nanofilaments, as well as many suggested mechanisms of growth and different potential applications in catalysis.

Many authors have suggested the application of carbon nanofibers as catalyst support ${ }^{7-9}$ due to: i) their good metal/support interaction caused by the presence of the prismatic planes on the nanofibers surface, ii) their high specific surface area that offers a better contact reactants/active sites and iii) absence of the ink-bottled pores that reduces the diffusion phenomena, mainly in liquid phase reactions or high mass and heat transfers reactions. However, the direct use of these 1D carbon materials in conventional catalytic reactors, especially in fixed-bed configuration, is significantly hampered by their nanoscopic size. Indeed, the nanoscopic size of the carbon nanofibers can cause reactor loading problems and pressure drop which render their use in a large scale reactor configuration impossible. In order to eliminate these drawbacks, it has developed a new kind of carbon nanofibers based composites, combining the macroscopic form with the nanomaterial characteristics. This procedure consists in raising carbon nanofibers on a macroscopic surface (felt, foam, fabric...) with a pre-defined form by the CVD method. Therefore, supporting carbon nanofibers on a macroscopic host allows the conservation of their advantages while diffusional phenomena can be suppressed ${ }^{10}$. The aim of this article is to report a brief review of the results obtained in the application of carbon nanofibers composites as catalytic support in various industrial processes.

\section{Synthesis of Carbon Nanofibers}

The macroscopic host structures used were graphite felt or fabric (Carbone Lorraine Co.) which was constituted of a dense entangled network of micrometer graphite filaments with a smooth surface. The starting graphite host had almost no porosity which was in good agreement with its extremely low specific surface area $\left(<1 \mathrm{~m}^{2} \cdot \mathrm{g}^{-1}\right)$. These materials were cut into a pre-defined shape, in cylindrical tablets or disks with appropriate dimensions to the desirable application. The tablets/disks were further impregnated with $1 \%$ wt. of nickel, using an alcoholic solution (20 vol.\% ethanol) of nickel nitrate (Acros). The solid was dried overnight at ambient temperature, followed by an oven dried at $100{ }^{\circ} \mathrm{C}$ and calcination at $350{ }^{\circ} \mathrm{C}$, both for 2 hours. The sample was placed inside a quartz reactor housed in an electrical oven. After 1 hour of in situ reduction at $400{ }^{\circ} \mathrm{C}$, the hydrogen flow was replaced by a mixture of hydrogen and ethane (Air Liquid) 
with a molar ratio of 5:1 $\left(\mathrm{H}_{2}: \mathrm{C}_{2} \mathrm{H}_{6}\right)$. The carbon nanofibers were obtained by catalytic hydrocarbon decomposition over the graphite material supported nickel catalyst at $680^{\circ} \mathrm{C}$ for 2 hours with a yield of 100 wt. $(\%)^{11}$. Figure 1a shows that after synthesis the surface of the felt was completely covered by a layer of carbon nanofibers. The formation of the carbon nanofibers on the macroscopic graphite felt went along with a significant increase in the specific surface area, i.e. $85 \mathrm{~m}^{2} \cdot \mathrm{g}^{-1}$, of the final composite taking into account the low surface area $\left(1 \mathrm{~m}^{2} \cdot \mathrm{g}^{-1}\right)$ of the starting felt. Surface area was measured using a Coulter SA-3100 sorptometer with $\mathrm{N}_{2}$ as adsorbant at liquid nitrogen temperature. Before measurement the samples were outgased at $200{ }^{\circ} \mathrm{C}$ for 2 hours in order to desorb moisture and other weakly adsorbed residues.

The nanofibers prepared by this technique exhibited homogeneous diameters (around $30 \mathrm{~nm}$ ) and fishbone structure with exposed prismatic planes (Figure 1b). The images was performed on a Scanning Electron Microscopy (SEM) JEOL model 6700 F.

The carbon nanofibers composite can be efficiently used as catalytic support in reactions where diffusional phenomena of the reactants are essential and in reactions with high mass and heat transfers. Moreover, the high thermal conductivity of the carbon based support allows a fast homogenization of the heat generated during the reaction throughout the catalyst body, preventing the formation of hot spots which are detrimental to the active phase dispersion and catalyst body conservation.

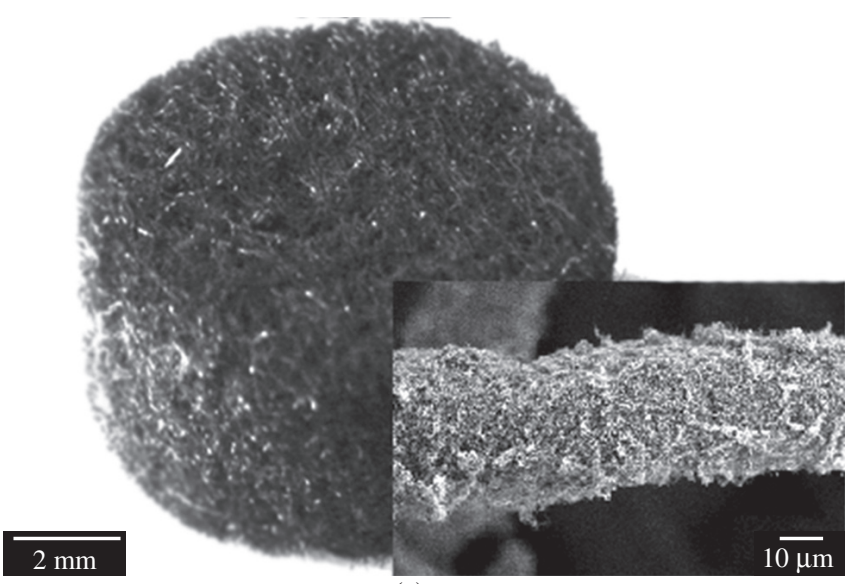

(a)

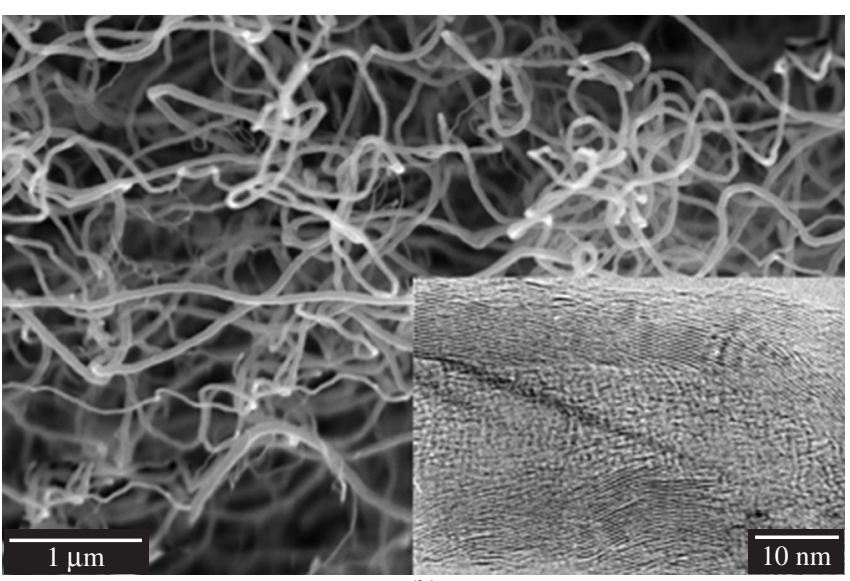

(b)

Figure 1. a) Image of a carbon felt composite with the surface re-covered by carbon nanofibers; and b) SEM image of carbon nanofibers with homogeneous diameters and detail of its fishbone structure.

\section{Catalytic Reactions Using Carbon Nanofibers}

\subsection{Catalytic decomposition of hydrazine}

Nowadays, most of the satellites in orbit use liquid monopropellant hydrazine as propulsion subsystem for orbit correction and positioning operations ${ }^{12}$. The thrust is obtained by catalytic decomposition of the monopropellant on a highly loaded catalyst containing about 30 to $40 \mathrm{wt}$. (\%) of iridium supported on alumina. This catalyst is mainly constituted of a macro- and mesoporous network in order to increase the active sites accessibility. Carbon nanofibers based composites was proposed as an alternative catalytic support of iridium for hydrazine decomposition ${ }^{13}$. The composite was cut in cylinder forms and impregnated with 30 (wt.) \% of iridium from a solution of hexachloroiridic acid. The tests were carried out with a $2 \mathrm{~N}$ microthruster catalyst placed in a vacuum chamber that allowed simulating the pressure conditions in space ${ }^{14,15}$.

The tests were carried out under two hydrazine injection pressures, i.e., 22 and 5.5 bar, simulating the real conditions of the propellant reservoir pressure at the beginning and the end of the satellite life, in the beginning and in the end of its useful life, respectively. For each pressure 4 series of 100 short pulses and 1 duty cycle were performed. The catalyst bed was pre-heated at $120{ }^{\circ} \mathrm{C}$ for all tests. The carbon nanofibers based catalyst showed superior thrust performances than the reference catalyst (Figure 2). These better performances can be explained by the large metallic surface exposed on the carbon nanofibers based catalyst, despite of the mass introduced in the microthruster which is tenth times lower than the quantity used with the commercial catalyst. This performance can also be attributed to the more accessible of the reactant to the active sites owing to the open structure of the support, i.e. high external surface area and absence of ink-bottled pores. In this type of reaction, where the heat and mass transfers must be very fast, the reactant does not have time to penetrate into the pores and the main reaction occurs on the external surface of the catalyst grains.

\subsection{Synthesis of styrene}

The styrene synthesis is one of the ten largest industrial processes nowadays ${ }^{16}$. This monomer is involved in several polymers synthesis, and is industrially produced by the direct dehydrogenation of ethylbenzene at $600-680{ }^{\circ} \mathrm{C}$ over potassium promoted iron oxide catalyst. This strongly endothermic process suffers from drawbacks such as: thermodynamic limitations, an irreversible catalyst deactivation and a relatively low yield ( $>50 \%)$. The carbon nanotubes have been cited as a very active and promising alternative catalyst to the industrial catalyst, with a higher styrene yield and a lower reaction temperature ${ }^{17,18}$.

Delgado et. al. ${ }^{19}$ had shown that carbon nanofibers based composite is catalytically active in the oxidative dehydrogenation of the ethylbenzene under low temperatures. Figure 3 shows the performances obtained at temperatures ranging from 375 to $530{ }^{\circ} \mathrm{C}$ for total flows of $30 \mathrm{~mL} / \mathrm{min}$ and $8 \mathrm{~mL} / \mathrm{min}$. Under both conditions, increasing the temperature led to a slight decrease in the styrene selectivity. On the other hand, the selectivity was not strongly influenced by the space velocity, especially at lower temperatures. This implies that operating by combining a low temperature $\left(440^{\circ} \mathrm{C}\right)$ and a low space velocity results in high styrene yields $(38 \%)$ with a styrene selectivity (81\%) that could make such supported carbon nanofibers attractive for industrial applications, a low flow favoring reactant adsorption and a low temperature minimizing the combustion.

\section{3. $\mathrm{H}_{2} \mathrm{~S}$ oxidation into elemental sulfur}

Over the last few decades, sulfur recovery from the $\mathrm{H}_{2} \mathrm{~S}$-containing acid gases has become more and more important due to the 


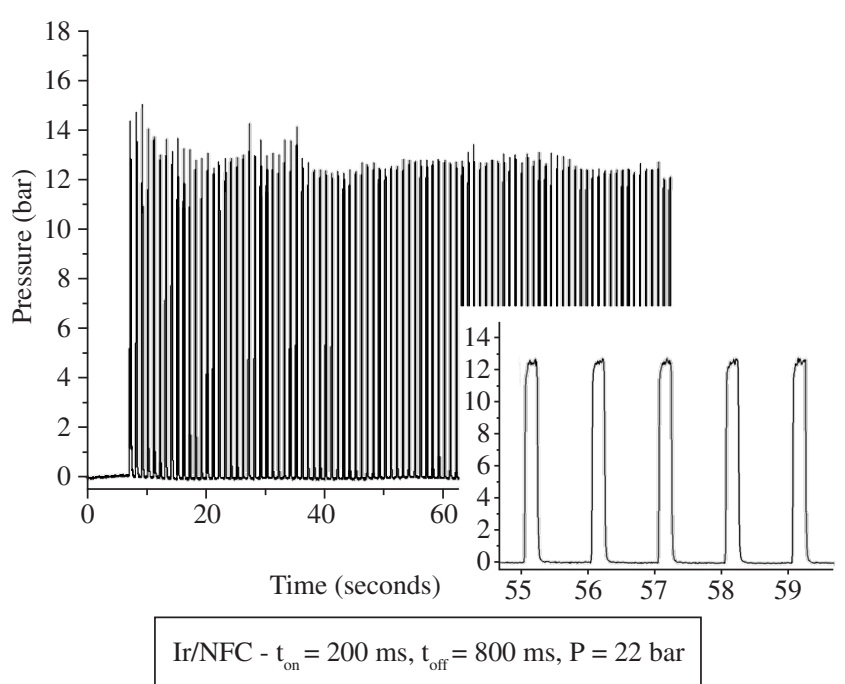

(a)

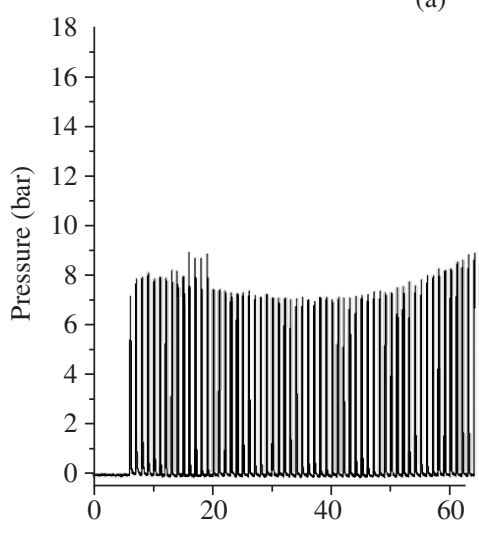

Time (seconds)

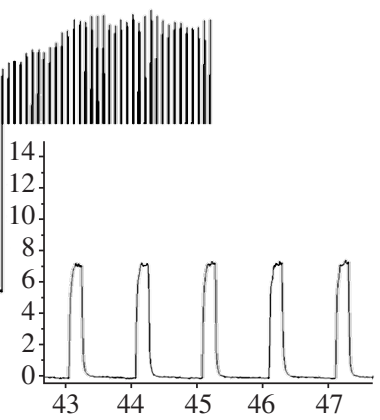

$\mathrm{Ir} / \mathrm{Al}_{2} \mathrm{O}_{3}-\mathrm{t}_{\mathrm{on}}=200 \mathrm{~ms}, \mathrm{t}_{\text {off }}=800 \mathrm{~ms}, \mathrm{P}=22 \mathrm{bar}$

(b)

Figure 2. Steady state (pulsed mode) performance variation of a) the carbon nanofibers based catalyst (Ir/CNF); and b) the commercial catalyst $\left(\mathrm{Ir} / \mathrm{Al}_{2} \mathrm{O}_{3}\right)$ from the chamber pressure curves of a series of 100 pulses $t_{\text {on }} 200 \mathrm{~ms}$ and $\mathrm{t}_{\text {off }} 800 \mathrm{~ms}$.

ever increasing standards of efficiency required by environmental protection pressures. The general trend is to selectively transform $\mathrm{H}_{2} \mathrm{~S}$ into elemental sulfur which is a valuable product, by the modified Claus process. However, due to thermodynamic limitations of the Claus equilibrium reaction, typical sulfur recovery efficiencies are only $90-96 \%$ for a two stage reactor plant and $95-98 \%$ for a three stage reactor plant ${ }^{20}$.

For this reason, new processes to deal with the Claus tail-gas were developed based on the direct oxidation of $\mathrm{H}_{2} \mathrm{~S}$ by oxygen working under the sulfur dew point typically between 100 and $120^{\circ} \mathrm{C}^{21}$.

Ledoux et al..$^{22}$ had shown the high activity and selectivity of the $\mathrm{NiS}_{2} / \beta-\mathrm{SiC}$ catalyst in the direct oxidation of the $\mathrm{H}_{2} \mathrm{~S}$ into elemental sulfur at low reaction temperature $\left(60^{\circ} \mathrm{C}\right)$. The total selectivity for sulfur was attributed to the absence of micropores in the support. The heterogeneous nature of the support surface (hydrophilic and hydrophobic areas) could explain the important role played by water to maintain a high and stable $\mathrm{H}_{2} \mathrm{~S}$ conversion level. The catalyst was submitted at frequently regenerations cycles due to the sulfur foul-

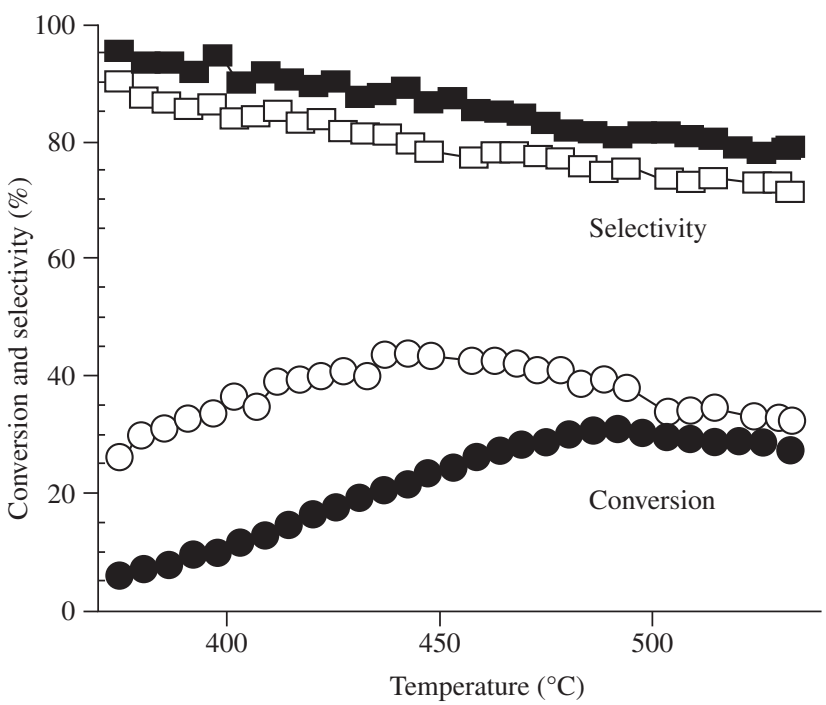

Figure 3. Ethylbenzene conversion curve $(\bigcirc, 0)$ and selectivity to styrene $(\square, \square)$ on the carbon nanofibers based composites as a function of the reaction temperature in the range $375-530{ }^{\circ} \mathrm{C}$, using total flow rate of $30 \mathrm{~mL} / \mathrm{min}(\boldsymbol{\bullet}, \square)$ and $8 \mathrm{~mL} / \mathrm{min}(\bigcirc, \square)$.

ing of the catalyst surface. Later, Nhut et. al. ${ }^{23}$ had suggested the use of nickel sulfide supported on carbon nanotubes based composites for the direct oxidation of $\mathrm{H}_{2} \mathrm{~S}$ into $\mathrm{S}$ at low temperature. The use of carbon nanofibers based composites led to a significant increase in the overall catalytic performance, both in terms of desulphurization activity and resistance to the solid sulfur deposition onto the material as compared to the reference catalyst supported on macroscopic SiC grains (Figure 4a). The high capacity of solid sulfur storage on the carbon nanofibers was attributed to the large void volume outside the carbon nanofibers composites and its particular mode of sulfur evacuation. This element is continuously removed outside of the composite by the formed water due the hydrophobicity of nanofibers (Figure $4 \mathrm{~b}$ ), letting the active sites exposed for further time.

\subsection{Electrode for fuel cells}

Electrode structure in PEM fuel cells has been improved from a two layers to a three layers system constituted by a conductive porous support, a diffusion layer and the catalyst itself. The performances of the electrodes depend on many parameters: i) type of macroscopic carbon support (carbon paper, carbon cloth, etc.) and its characteristics (porosity and thickness); ii) type of catalyst (metal, metal amount, particles size, type of catalyst support); iii) thermal treatment; iv) thickness of diffusion and catalytic layers; and v) fabrication process (screen-printing, rolling, brushing, filtering or spraying) ${ }^{24}$.

The peculiar electronic, adsorption, mechanical and thermal properties suggest that CNTs are suitable materials for electrodes and catalysts supports in PEM fuel cells ${ }^{25}$. Recently Gangeri et al. ${ }^{26}$ evaluated the electrocatalytic performance of platinum supported on carbon nanofibers deposited on felt (Pt/CNF/felt) and fabric (Pt/CNF/fabric) as alternative electrodes for PEM fuel cells. The author compared the performance of these new nanostructured platinum carbon materials with those of a commercial Pt-carbon black on carbon cloth electrode in a $1 \mathrm{~cm}^{2}$ fuel cell working at room temperature. The analysis of polarization curves (Figure 5) indicated that CNF composites are better electrocatalysts than commercial ones, showing the lowest ohmic losses and mass transport losses, besides the high adsorption capacity of hydrogen on carbon nanofibers. 


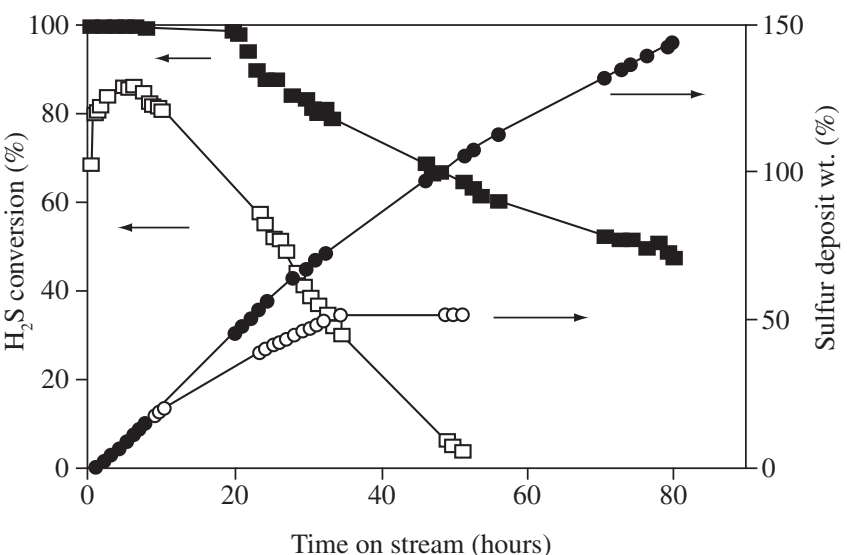

(a)

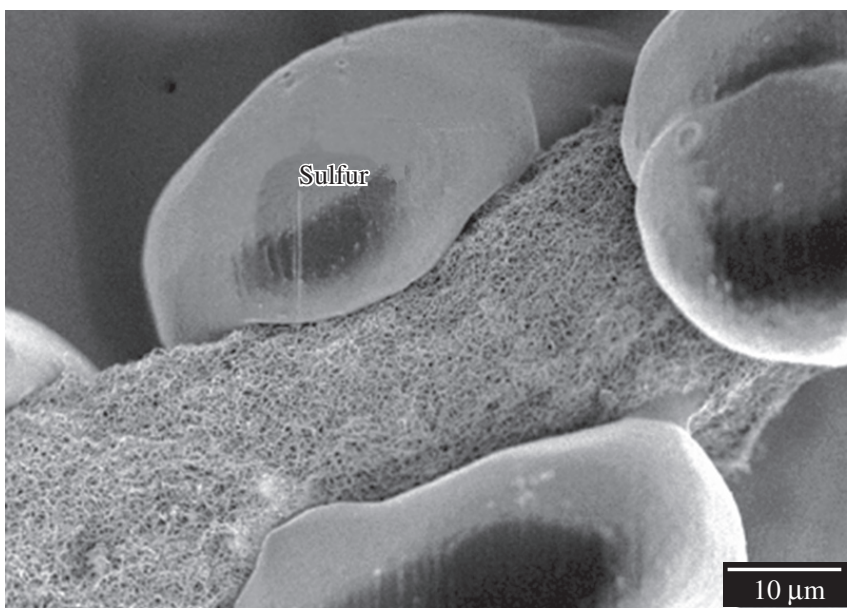

(b)

Figure 4. a) $\mathrm{H}_{2} \mathrm{~S}$ conversion and sulfur deposition as a function of time on $5 \% \mathrm{NiS}_{2} / \mathrm{SiC}$ catalyst $(\mathrm{O}, \square)$ and $5 \% \mathrm{NiS}_{2} / \mathrm{CNF}$ based composites $(\boldsymbol{\bullet}, \mathbf{\square})$. Experimental conditions: $2500 \mathrm{ppm}$ of $\mathrm{H}_{2} \mathrm{~S}, 4000 \mathrm{ppm}$ of $\mathrm{O}_{2}, 30 \mathrm{vol} . \%$ of $\mathrm{H}_{2} \mathrm{O}$, WHSV $=0.03 \mathrm{~h}^{-1}, \mathrm{~T}=60^{\circ} \mathrm{C}$; and b) SEM micrographs of the particular mode of sulfur deposition on carbon nanofibers.

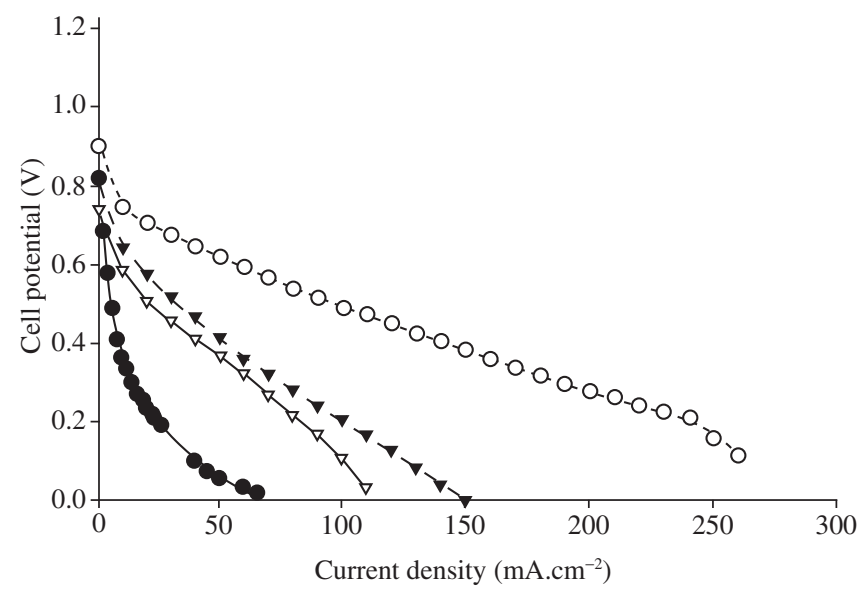

Figure 5. Polarization curves for the different classes of electrodes: $(\bigcirc) 20 \%$ of Pt nanoparticles on the commercial catalyst (E-tek), ( $\mathbf{\Delta}) 5 \% \mathrm{Pt} / \mathrm{CNF} / \mathrm{fabric}$, $(\triangle)$ ) $20 \% \mathrm{Pt} / \mathrm{CNF} /$ felt, and $(-) 20 \% \mathrm{Pt}$ on commercial catalyst (E-tek).

\section{Perspectives}

\subsection{Ammonia decomposition}

The catalytic decomposition of ammonia appears to be an appealing process for clean hydrogen production. Recently, Yin et. al. ${ }^{27}$ has reported that very small Ru nanoparticles on carbon nanotubes have high activity in ammonia catalytic decomposition. The excellent performances of $\mathrm{Ru} / \mathrm{CNT}$ and $\mathrm{K}-\mathrm{Ru} / \mathrm{CNT}$ were related to the high dispersion of $\mathrm{Ru}$ and to the high graphitization and purity of CNTs. The authors have investigated also the influence of the support in catalyst activity. Moreover, the order of ammonia conversion was ranked as $\mathrm{Ru} / \mathrm{CNT}>\mathrm{Ru} / \mathrm{MgO}>\mathrm{Ru} / \mathrm{TiO}_{2}>\mathrm{Ru} / \mathrm{Al}_{2} \mathrm{O}_{3}>\mathrm{Ru} / \mathrm{ZrO}_{2}>$ $\mathrm{Ru} / \mathrm{AC}$.

We suggested carbon nanofibers composite as a support for ruthenium metal for the catalytic decomposition of ammonia. The catalytic performances are compared with those obtained on the same catalysts loaded on carbon nanotubes based support. The Figure 6 shows the better performance of the carbon nanofibers based support due to its opened structure, reducing thus the diffusion problems.

\subsection{Total combustion of methane}

Catalytic combustion of methane has attracted attention in the field of emission control. $\mathrm{Pd} / \mathrm{ZnO}_{2}$ based catalysts are notorious for their high activity in methane oxidation ${ }^{28}$. However, the drawback with these catalysts is their instability, resulting in the reduction of activity during operation. The decrease of conversion has also been attributed to the inhibition from the water generated during the oxidation process. This phenomena is related to the inactive hydroxyls groups formed on the catalysts surface, which block the access into the $\mathrm{PdO}$ sites for methane dissociation ${ }^{29}$. Therefore, if water inhibition is the cause for deactivation, carbon nanofibers based composites could be a good solution to improve palladium catalysts water resistance due its hidrophobicity properties.

\section{Conclusions}

In summary, carbon nanofibers composites with macroscopic shaping can be efficiently employed as a new class of catalyst support which exhibits a high catalytic activity along with peculiar product selectivity when compared to those observed on traditional catalysts

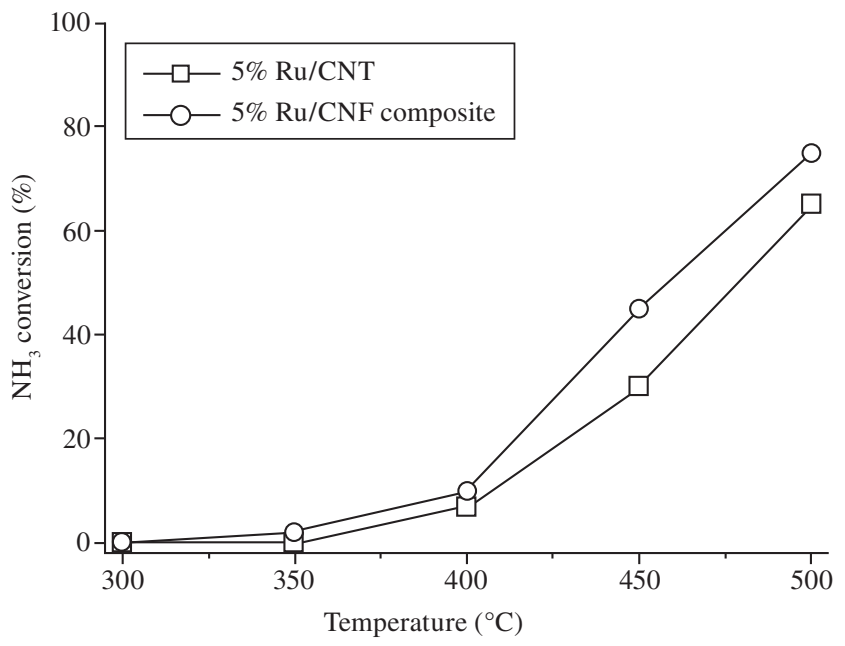

Figure 6. Conversion curve of ammonia in function of the temperature on the $5 \% \mathrm{Ru} / \mathrm{CNF}(\mathrm{O})$ and $5 \% \mathrm{Ru} / \mathrm{CNT}$ catalyst $(\square)$. 
in several catalytic reactions. The high catalytic performances of the carbon nanofibers based catalyst were attributed to i) the high external surface area and morphology of the support which allows rapid access of the reactants to the active sites and ii) the high thermal conductibility of the support which allows the rapid evacuation of the heat formed during the reaction and favors the temperature homogenization throughout the catalyst bed. Finally, it should be noted that the complete absence of bottled pores allows the rapid $3 \mathrm{D}$ access of the entire volume of the catalyst to the reactants and also the rapid evacuation of the products which significantly lowers secondary reactions.

\section{Acknowledgments}

The authors would like to thank the FAPESP for supporting part of the work.

\section{References}

1. Robertson SD. Graphite formation from low temperature pyrolysis of methane over some transition metal surfaces. Nature 1969; 221(5185):1044-1046.

2. Baker RTK, Barber MA, Harris PS, Faetes FS, Waite RJ. Nucleation and growth of carbon deposits from the nickel catalyzed decomposition of acetylene. Journal of Catalysis 1972; 26(1):51-62.

3. Kroto HW, Heath JR, O'Brien SC, Curl RF, Smalley RE. C60: Buckminsterfullerene. Nature 1985; 318(6042):162-163.

4. Iijima S. Helical microtubules of graphitic carbon. Nature 1991; 354(6348):56-58.

5. Ebbesen TW, Ajayan PM. Large-scale synthesis of carbon nanotubes. Nature 1992; 358(6383):220-222.

6. Jong KP, Geus JW. Carbon nanofibers - Catalytic synthesis and applications. Catalysis Review Science and Engineering 2000; 42(4):481-510.

7. Rodriguez NM, Kim MS, Baker RTK. Carbon nanofibers: A unique catalyst support medium. Journal of Physical Chemistry 1994; 98(50):13108-13111.

8. Salman F, Park C, Baker RTK. Hydrogenation of crotonaldehyde over graphite nanofibers supported nickel. Catalysis Today 1999; 53(3):385-394.

9. Pham-Huu C, Keller N, Charbonniére R, Ziessel R, Ledoux MJ. Carbon nanofibers supported palladium catalyst for liquid-phase reactions. An active and selective catalyst for hydrogenation of $\mathrm{C}=\mathrm{C}$ bonds. Chemical Communications 2000; 19:1871-1872.

10. Pham-Huu C, Vieira R, Charbonnière L, Ziessel R, Ledoux MJ. Composites based on carbon nanotubes deposited on an activated support for application in catalysis. French Pat. 0115178; 2001.

11. Vieira R, Ledoux MJ, Pham-Huu C. Synthesis and characterisation of carbon nanofibers with macroscopic shaping formed by catalytic decomposition of $\mathrm{C}_{2} \mathrm{H}_{6} / \mathrm{H}_{2}$ over nickel catalyst. Applied Catalysis A: General 2004; 274(1-2):1-8.

12. Soares Neto TG, Cobo AJG, Cruz GM. Textural properties evolution of Ir and Ru supported on alumina catalysts during hydrazine decomposition in satellite thruster. Applied Catalysis A: General 2003; 250(2):331-340.
13. Vieira R, Pham-Huu C, Keller N, Ledoux MJ. New carbon nanofibers/ graphite felt composite for use as a catalyst support for hydrazine catalytic decomposition. Chemical Communications 2002; 9:954-955.

14. Vieira R, Bastos-Netto D, Ledoux MJ, Pham-Huu C. Hydrazine decomposition over iridium supported on carbon nanofibers composite for space applications: Near actual flight conditions tests. Applied Catalysis A: General 2005; 279(1-2):35-40.

15. Vieira R, Bernhardt P, Pham-Huu C, Ledoux MJ. Performance comparison of $\mathrm{Ir} / \mathrm{CNF}$ and $\mathrm{Ir} / \mathrm{Al}_{2} \mathrm{O}_{3}$ catalysts in a $2 \mathrm{~N}$ hydrazine microthruster. Catalysis Letters 2005; 99(3-4):177-180.

16. James DH, Castor WM. Styrene. Ullmann's encyclopedia of industrial chemistry, A25. New York: John Wiley \& Sons; 1994.

17. Guerrero-Ruiz A, Rodriguez-Ramos I. Oxydehydrogenation of ethylbenzene to styrene catalyzed by graphites and activated carbons. Carbon 1994; 32(1):23-29.

18. Mestl G, Maksimova NI, Keller N, Roddatis VV, Schlögl R. Nanofilaments in heterogeneous catalysis: An industrial application for new carbon materials. Angewandte Chemie International Edition 2001; 40(11):2066-2068

19. Delgado JJ, Vieira R, Rebmann G, Su DS, Keller N, Ledoux MJ, Schlögl R. Supported carbon nanofibers for the fixed-bed synthesis of styrene. Carbon 2006; 44(4):809-812.

20. Wieckowska J. Catalytic and adsorptive desulphurization of gases. Catalysis Today 1995; 24(4):405-465.

21. Savin S, Nougayrède JB, Willing W, Bandel G. New developments in sulfur recovery process technology. International Journal of Hydrocarbon Engineering 1998; 3(4):54-56.

22. Ledoux MJ, Pham-Huu C, Keller N, Nougayrède JB, Savin-Poncet $\mathrm{S}$, Bousquet J. Selective oxidation of $\mathrm{H}_{2} \mathrm{~S}$ in Claus tail-gas over $\mathrm{SiC}$ supported $\mathrm{NiS}_{2}$ catalyst. Catalysis Today 2000; 61(1):157-163.

23. Nhut JM, Vieira R, Keller N, Pham-Huu C, Boll W, Ledoux MJ. Carbon composite-based catalysts: new perspectives for low-temperature $\mathrm{H}_{2} \mathrm{~S}$ removal. Studies in Surface Science and Catalysis 2002; 143:983-991.

24. Maoka T. Electrochemical reduction of oxygen on small Pt particles supported on carbon in concentrated phosphoric acid. II Effects of Teflon content in the catalyst layer and baking temperature of the electrode. Electrochimica Acta. 1988; 33(3):379-383.

25. Serp P, Corrias M, Kalck P. Carbon nanotubes and nanofibers in catalysis. Applied Catalysis A: General 2003; 253(2):337-358.

26. Gangeri M, Centi G, La-Malfa A, Perathoner S, Vieira R, Pham-Huu C, Ledoux MJ. Electrocatalytic performances of nanostructured platinumcarbon materials. Catalysis Today 2005; 102-103:50-57.

27. Yin SF, Xu BQ, Ng CF, Au CT. Nano Ru/CNTs: A highly active and stable catalyst for the generation of $\mathrm{CO}_{x}$-free hydrogen in ammonia decomposition. Applied Catalysis B: Environmental B 2004; 48(4):237-241.

28. Ciuparu D, Lyubovsky MR, Altman E, Pfefferle LD, Datye A. Catalytic combustion of methane over palladium-based catalysts. Catalysis Reviews 2002; 44(4):593-664.

29. Perssona K, Pfefferleb LD, Schwartzb W, Erssona A, Jarás SG. Stability of palladium-based catalysts during catalytic combustion of methane: The influence of water. Applied Catalysis B: Environmental 2007; $74(3-4): 242-250$. 
